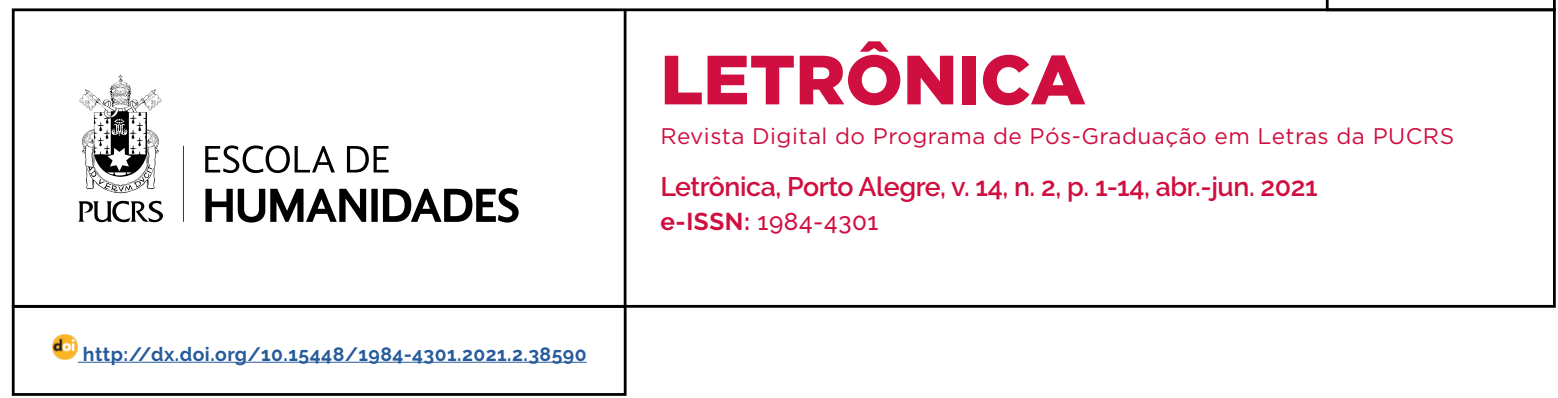

SEÇÃO: ARTIGOS

\title{
Compreensão de textos de diferentes tipos por crianças da Educação Infantil
}

\author{
Comprehension of texts of different types by children of Early Childhood Education
}

\author{
Jacqueline Travassos \\ de Queiroz ${ }^{1}$ \\ orcid.org/0000-0001-7426-8323 \\ jacqueline.queiroz@upe.br
}

\author{
Alina Galvão Spinillo \\ orcid.org/0000-0002-6113-4454 \\ alinaspinillo@hotmail.com
}

\section{Lianny Milenna de Sá \\ Melo $^{3}$}

orcid.org/0000-0002-9890-0597

lianny_melo@hotmail.com

Recebido em: 14/7/2020.

Aprovado em: 15/10/2020.

Publicado em: 10/08/2021.
Resumo: O estudo investigou a compreensão oral de textos narrativos, expositivos e argumentativos em crianças da Educação Infantil. O objetivo principal foi examinar se o nivel de compreensão variaria em função do tipo de texto e identificar a natureza das dificuldades experimentadas pelas crianças em relação ao estabelecimento de inferências em cada um desses textos. Trinta crianças (média de idade de 5 anos e 8 meses) foram solicitadas a responder perguntas de natureza inferencial (causal e estado) sobre cada um dos textos que the foram lidos. Verificou-se que o nivel de compreensão variava em função dos textos, visto que as crianças tinham mais facilidade em compreender o texto narrativo que os demais textos. Por outro lado, apresentaram o mesmo nível de dificuldade no texto expositivo e argumentativo. A principal dificuldade identificada foi em relação à compreensão das relações de causalidade no texto expositivo. Implicações educacionais são discutidas no sentido de promover intervenções precoces para desenvolver a compreensão oral de textos antes mesmo que a criança saiba ler. Essa implicação confere à Educação Infantil papel relevante no desenvolvimento de habilidades linguísticas que são preditoras da compreensão leitora em anos escolares subsequentes.

Palavras-chave: Compreensão oral de textos. Tipos de textos. Inferências. Educação infantil.

Abstract: The study investigated the listening comprehension of narrative, expository and argumentative texts in children of Early Childhood Education. The objective was to examine whether the level of understanding would vary according to the type of text, and to identify the nature of the difficulties experienced by children in relation to the establishment of inferences in each of these texts. Thirty children (mean age of 5 years and 8 months) were asked to answer inferential questions (causal and state) about each of the texts that were read to them. It was found that the level of comprehension varied according to the texts, since the children were more likely to understand the narrative text than the other ones. On the other hand, children showed the same level of difficulty in the expository and argumentative text. The main difficulty identified was in relation to the understanding of the causal relations in the expository text. Educational implications are discussed to promote early interventions to develop listening comprehension of texts even before the child can read. This implication gives Early Childhood Education a relevant role in the development of language skills that are predictors of reading comprehension in subsequent school years.

Keywords: Listening comprehension of texts. Textual types. Inferences. Early childhood education. 


\section{Introdução}

Tema há muito e amplamente investigado na literatura, a compreensão de textos por crianças, sejam orais ou escritos, continua sendo objeto de interesse por parte de estudiosos de diferentes afiliações teóricas e de diferentes campos do conhecimento como a Psicologia, a Educação e a Psicolinguística. Esse interesse decorre do fato de ser um fenômeno complexo que possui múltiplas dimensões (SPINILLO, 2013) e do fato de ser relevante para o sucesso acadêmico em todas as áreas do conhecimento e em todos os anos escolares. É expressivo o número de pesquisas que examinam os fatores relativos ao perfil linguístico e cognitivo das crianças ao tentarem compreender o texto com o qual se deparam. Esses fatores se referem à memória de trabalho, capacidade de decodificar (no caso da leitura do texto pela criança), domínio do vocabulário, monitoramento, estabelecimento de inferências (KING, 2007) e aos conhecimentos sobre o conteúdo do texto (BRANDÃO; OAKHILL, 2005). Há estudos, entretanto, que investigam fatores externos à criança, como por exemplo, a natureza da situação de investigação em que ela interage com o texto, ou seja, o método adotado para avaliar sua compreensão (SPINILLO; HODGES, 2013); e as características estruturais do texto a ser compreendido (SPINILLO; ALMEIDA, 2014).

Verifica-se que a grande maioria das pesquisas com crianças utiliza o texto narrativo, em particular, a história. O segundo gênero de texto mais investigado é o expositivo, sendo raros os estudos que investigam outros gêneros textuais, como por exemplo, o argumentativo. Pesquisas que utilizam o texto expositivo avaliam a compreensão leitora de crianças já alfabetizadas e estudantes universitários (KENDEOU; BROEK, 2007; MCNAMARA, 2007; OZURU et al., 2007; WOLFE, 2005).

Em menor número são as pesquisas com texto argumentativo, sendo geralmente realizadas com adolescentes e estudantes universitários (DIAKIDOY et al., 2015; DIAKIDOY; IOANNOU; CHRISTODOULOU, 2017; TENGBERG; OLIN-SCHELLER, 2016). Na realidade, raros são os estudos que avaliam a compreensão de texto argumentativo em crianças, como o de Almeida, Spinillo e Lima (2019). Nesta investigação, os participantes, com idades entre 8 e 9 anos, foram solicitados a responder perguntas de natureza inferencial sobre um texto de opinião a respeito do uso do computador por crianças. Um dos principais resultados foi que as crianças não tinham dificuldades para identificar as justificativas que apoiavam os pontos de vista divergentes sobre o assunto; contudo, apresentavam dificuldades em determinar quem eram os personagens que apresentavam um ou o outro ponto de vista, ou seja, em associar um determinado ponto de vista a seu defensor.

Há pesquisas cujo objetivo é comparar a compreensão leitora em textos de diferentes tipos. ${ }^{4}$ Resultados obtidos com crianças entre 9 e 11 anos apontam para um melhor desempenho em textos narrativos do que expositivos (BAŞTUĞ, 2014; ÇAKIR, 2008; MCNAMARA; OZURU; FLOYD 2011). A explicação para esses resultados, segundo os autores, é que os estudantes possuem um bom domínio do esquema narrativo, o que teria favorecido a compreensão e que o conhecimento prévio teve efeito maior no texto expositivo do que no narrativo, visto que o conhecimento sobre o conteúdo era mais necessário no texto expositivo. A conclusão foi que a estrutura do texto e as informações neles veiculadas são mais familiares no texto narrativo do que em textos expositivos.

Outras pesquisas investigam textos narrativos e argumentativos. Spinillo e Almeida (2014), por exemplo, em estudo com crianças de 9 anos, examinaram o papel desempenhado pelas caracteristicas estruturais e predominantes de textos de diferentes gêneros no estabelecimento de diferentes tipos de inferências (causais, de estado

\footnotetext{
4 Marcuschi (2008) faz uma distinção entre tipo e gênero textual que é adotada neste artigo. O tipo textual é definido como uma espécie de construção teórica determinada pela natureza linguística que o compõe (aspectos sintáticos, lexicais, tempos verbais, relações lógicas), caracterizando-se mais como sequências linguisticas predominantes do que como textos materializados. Os gêneros textuais, por sua vez, referem-se aos textos materializados, compostos por sequências tipológicas que são relacionadas entre si, e que possuem função sociocomunicativa. Portanto, quando se denomina um texto como argumentativo ou narrativo, por exemplo, não está nomeando o gênero e sim um predomínio de uma sequência tipológica.
} 
e de previsão). Por meio da metodologia on-line ${ }^{5}$ de investigação, as crianças respondiam perguntas inferenciais sobre o conteúdo dos textos e perguntas de explicação em que justificavam as respostas dadas. Observou-se que respostas mais apropriadas e completas eram fornecidas em relação ao texto narrativo, enquanto respostas apropriadas e incompletas eram mais frequentes no texto argumentativo. Os dados mostraram, ainda, que em ambos os textos as inferências causais e de estado eram mais fáceis de serem estabelecidas do que as de previsão. Essa dificuldade era mais acentuada no texto narrativo do que no argumentativo. ${ }^{6}$

Melo (2017) examinou as relações entre compreensão de textos narrativo e argumentativo e tipos de inferências (causais e de previsão) em alunos do $3 .^{\circ}$ ao $5 .^{\circ}$ ano do Ensino Fundamental, com idade entre 8 e 10 anos. A pesquisa envolveu dois estudos voltados para aspectos específicos: um sobre as inferências de previsão e outro sobre as inferências causais. O primeiro tratava das inferências de previsão em dois textos narrativos: história e relato de experiência pessoal. O objetivo era examinar se a natureza do conteúdo veiculado nos textos (fictício e não fictício na história e no relato, respectivamente) teria papel importante na compreensão. O segundo estudo investigou as inferências causais em textos narrativo e argumentativo. O objetivo era examinar se a natureza das relações de causalidade que caracterizam esses tipos de textos teria papel importante na compreensão, visto que no narrativo as relações de causalidade são de causa e efeito, enquanto no texto argumentativo tais relações são justificativas que sustentam pontos de vista distintos defendidos por interlocutores acerca de um dado tema polêmico. A tarefa consistia, em ambos os estudos, na leitura interrompida do texto (metodologia on-line), realizada de forma conjunta pela examinadora e pelo participante. Após a leitura de cada parte do texto, o estudante respondia perguntas inferenciais e perguntas de explicação em que justificavam as respostas fornecidas.

Os resultados do primeiro estudo mostraram que as inferências de previsão foram mais facilmente estabelecidas no texto narrativo de ficção (história) do que no texto de não ficção (relato), indicando que a capacidade de fazer previsões plausiveis e apropriadas varia em função do texto que está sendo compreendido e que a ficção favorece as inferências de previsão. No segundo estudo, verificou-se que a natureza das relações de causalidade (causa e efeito vs. justificativa) não teve efeito sobre o desempenho. Esse resultado sugere que estabelecer inferências causais pode ser uma habilidade geral que se manifesta de forma semelhante em textos narrativo e argumentativo, independentemente das especificidades com que se configurem em cada um desses textos.

Apesar do interesse crescente em investigar as relações entre compreensão e tipos de textos, ainda são necessários mais estudos que venham fornecer um quadro mais substancial de informações acerca dessas relações, de modo que a presente pesquisa se propõe a contribuir com esse quadro, examinando a compreensão de textos narrativos, argumentativos e expositivos em crianças. De forma adicional, dada a lacuna na área, o estudo investiga crianças da Educação Infantil que ainda não dominam a leitura e a escrita.

Diante da escolha dessa população, torna-se relevante comentar que a compreensão textual, de maneira mais ampla, envolve tanto a compreensão de textos escritos como de textos oralmente apresentados. No primeiro caso, que se refere à compreensão leitora, aquele que compreende o texto é o próprio leitor do texto. No segundo caso, aquele que compreende o texto é aquele a quem a leitura de um texto é endereçada, ou seja, realizada em voz alta por outra pessoa. Esse segundo caso abre a possibilidade de investigar a compreensão de textos em indivíduos que ainda

\footnotetext{
5 A metodologia off-line se refere à investigação sobre a compreensão após a leitura completa do texto. Já a metodologia on-line ocorre durante a leitura do texto, de forma interrompida (SPINILLO; HODGES, 2013; SPINILLO; MAHON, 2015). Esta metodologia possibilita investigar inferências de previsão, tendo em vista que a interrupção do texto permite perguntas referentes a acontecimentos e episódios ainda não apresentados no texto.

6 A interpretação desse resultado foi documentada em estudo subsequente conduzido por Almeida, Spinillo e Lima (2019), apresentado anteriormente.
} 
não dominam a leitura, como é o caso de crianças que ainda não foram alfabetizadas. No Brasil, poucos são os estudos que investigam a compreensão de textos em crianças que ainda não sabem ler, possivelmente por acreditar-se que para se compreender textos é necessário saber lê-los primeiro. Tal crença, além de ser um equivoco, tem como consequência divorciar a compreensão de textos orais da compreensão leitora, indo de encontro a evidências empíricas que demonstram haver relações entre a compreensão de textos na modalidade oral e a compreensão leitora.

Cain e Oakhill (2007) e Diakidoy et al. (2005) comentam que muitos dos aspectos envolvidos na compreensão de textos orais estão também presentes na compreensão de textos escritos e que não há uma distinção clara entre a compreensão oral e a leitura. Por exemplo, Lepola et al. (2012) investigaram a influência de habilidades linguísticas e cognitivas (vocabulário, consciência fonológica, memória para sentenças, estabelecimento de inferências) no desenvolvimento da compreensão oral de histórias em crianças de 4 a 6 anos. De modo geral, essas habilidades influenciavam a compreensão oral, sobretudo a capacidade de estabelecer inferências que, com o passar do tempo, tinha um papel preditivo mais expressivo do que as demais habilidades avaliadas. Necessário ressaltar que essas mesmas habilidades desempenham papel igualmente importante na compreensão leitora, corroborando, assim, as afirmações daqueles autores.

O papel preditivo da compreensão oral sobre a compreensão leitora foi apontado por Kendeou et al. (2009) em estudo longitudinal em que acompanharam crianças dos 4 e 6 anos até os 8 anos de idade. A compreensão oral foi avaliada por meio da reprodução de uma história apresentada em áudio acompanhada de gravuras. A compreensão leitora foi avaliada quando as crianças tinham 8 anos, por meio da leitura de uma história e sua posterior reprodução. Os dados mostraram que a compreensão oral inicial predizia a compreensão leitora posterior, aos 8 anos, sendo responsável por mais variâncias na compreensão leitora do que a habilidade de decodificação.

A contribuição da compreensão oral e seu caráter preditivo sobre a compreensão leitora é documentado por outros pesquisadores (BERNINGER; ABBOTT, 2010; TOBIA; BONIFACCI, 2015). $\mathrm{Na}$ realidade, essa relação é de reciprocidade, pois a compreensão oral influencia a compreensão leitora que, por sua vez, tem impacto sobre a compreensão oral. Tais evidências justificam a necessidade de investigar a compreensão oral de crianças que ainda não leem, uma vez que, em última instância, a compreensão oral está associada à leitura no sentido amplo do termo, isto é, indo além do domínio do sistema de representação e abrangendo o significado do que é lido.7 Investigar esse fenômeno em crianças que ainda não sabem ler tem implicações aplicadas para a Educação Infantil, como será discutido adiante.

A partir dessas considerações, o presente estudo examinou a compreensão oral de textos de narrativos, expositivos e argumentativos em crianças não leitoras alunas dos anos finais da Educação Infantil. O objetivo principal foi avaliar se o nivel de compreensão variaria em função do tipo de texto, uma vez que possuem características estruturais que os diferenciam. Como objetivo específico, buscou-se identificar a natureza das dificuldades experimentadas pelas crianças em função dos tipos de inferências em cada um desses textos. $O$ interesse em identificar as dificuldades das crianças reside no fato de que os erros revelam formas de pensar, tendo, portanto, um valor de natureza psicológica, sobretudo no âmbito da cognição. Além disso, as dificuldades das crianças podem ser consideradas desafios a serem superados em situações de ensino, tendo, portanto, um valor de natureza educacional.

\section{Método}

\subsection{Participantes}

Trinta crianças alunas do último ano da Educação Infantil de escolas particulares localizadas na cidade

\footnotetext{
7 A relação intrínseca entre leitura e compreensão textual está presente no Modelo de Construção-Integração de Kintsch (1998) e no Modelo Simples de Leitura proposto por Hoover e Gough (1990).
} 
do Recife, com média de idade de 5 anos e 8 meses. Os participantes não apresentavam limitações intelectuais, motoras ou sensoriais. A participação das crianças foi voluntária, com o consentimento de seus responsáveis que assinaram o TCLE (Termo de Consentimento Livre e Esclarecido). A pesquisa foi aprovada pelo Comitê de Ética em Pesquisa da Universidade Federal de Pernambuco sob o número de CAAE 47073015.7.0000.5208.

\subsection{Procedimento}

Cada criança foi individualmente entrevistada em três sessões pela mesma examinadora, com tempo livre para sua realização e gravadas digitalmente em áudio, com um intervalo de 7 a 10 dias entre elas.

Em cada sessão era lido um texto para a criança e em seguida eram feitas perguntas de natureza inferencial. Três textos foram apresentados: um texto narrativo que consistia em uma história (Anexo A), um texto argumentativo (Apêndice A) e um texto expositivo (Anexo B).

A história apresentada (190 palavras) foi adaptada daquela elaborada por Brandão e Spinillo (1998), o texto argumentativo (174 palavras) foi elaborado especialmente para esta investigação e o expositivo (170 palavras) foi o mesmo utilizado por Saraiva, Moojen e Munarski (2009).

A ordem de apresentação dos textos em cada sessão foi randomizada da seguinte maneira: para 10 participantes na primeira sessão era apresentado o texto narrativo, na segunda sessão o texto expositivo e na terceira o argumentativo; para outros 10 participantes a ordem era argumentativo, narrativo e expositivo; e para outros 10 participantes a ordem era expositivo, argumentativo e narrativo.

Em cada sessão, após a leitura do texto pela examinadora, eram feitas seis perguntas inferenciais, sendo três causais e três de estado, conforme descrito no Quadro 1 (narrativo), Quadro 2 (argumentativo), Quadro 3 (expositivo) e nas descrições relativas a cada texto apresentado. Importante comentar que a classificação das perguntas em causais e de estado tomou por base a classificação proposta por Graesser, Singer e Trabasso (1994) a respeito da natureza das inferências que decorrem das conexões estabe- lecidas no texto e associadas ao conhecimento de mundo daquele que interage com o texto. Esses dois tipos de inferências estão presentes na maioria das classificações adotadas na literatura, como discute Coscarelli (2002), ainda que com outras terminologias. Além disso, essas inferências são possiveis de serem estabelecidas em textos narrativos, expositivos e argumentativos.

Em cada sessão, a ordem de apresentação das perguntas era fixa, de acordo com a sequência em que as informações eram veiculadas no texto.

\subsubsection{Os textos investigados e suas perguntas}

\subsubsection{O texto narrativo}

No texto narrativo, no caso, a história, as perguntas inferenciais de estado se referiam a informações implícitas sobre o tempo, local, personagens e eventos. As perguntas causais versavam sobre relações de causa e efeito entre os eventos, sentimentos, motivações e as ações dos personagens.

Quadro 1 - Perguntas inferenciais relativas ao texto narrativo

\begin{tabular}{|c|c|}
\hline \multicolumn{2}{|l|}{ Texto narrativo } \\
\hline Pergunta & Tipo \\
\hline $\begin{array}{l}\text { 1. Por que as árvores grandes não } \\
\text { gostavam da flor? }\end{array}$ & Causal \\
\hline 2. O que a flor mais queria? & Estado \\
\hline $\begin{array}{l}\text { 3. O que foi que o passarinho fez } \\
\text { para ajudar a flor? }\end{array}$ & Estado \\
\hline $\begin{array}{l}\text { 4. Por que o quintal ficou parecendo } \\
\text { um lindo jardim? }\end{array}$ & Causal \\
\hline $\begin{array}{l}\text { 5. O que fez as sementes crescerem } \\
\text { tão rápido? }\end{array}$ & Causal \\
\hline $\begin{array}{l}\text { 6. Quem eram as amigas da florzi- } \\
\text { nha no final da história? }\end{array}$ & Estado \\
\hline
\end{tabular}

Fonte: As autoras.

Para responder a primeira pergunta ("Por que as árvores grandes não gostavam da flor?") de forma apropriada, seria necessário inferir que a razão das árvores não gostarem da flor estava relacionada a alguma característica da flor (bonita 
e delicada) que a tornava diferente das árvores (grandes e feias). Essa inferência seria possivel de ser estabelecida a partir da integração de duas passagens presentes no texto: "Era uma vez uma flor que morava num quintal cheio de árvores grandes e feias. A flor era muito bonita $\mathrm{e}$ delicada e chamava a atenção de todos que por lá passavam" e "As árvores grandes não gostavam dela e nunca a convidavam para brincar".

Na segunda pergunta ("O que a flor mais queria?"), a resposta apropriada referia-se ao objetivo da personagem principal em ter alguém com quem pudesse conversar e brincar.

A resposta correta para a terceira pergunta ("O que foi que o passarinho fez para ajudar a flor?") estava relacionada à ação do passarinho para ajudar a flor a alcançar seu objetivo. No caso, a ação realizada foi dirigir-se a um jardim vizinho apanhar sementes de flores e plantá-las no quintal onde a florzinha morava para que, assim, nascessem outras flores com as quais pudesse conversar e brincar.

A resposta correta para a quarta pergunta ("Por que o quintal ficou parecendo um lindo jardim?") requeria integrar aquilo que era veiculado no texto sobre a ação do passarinho (pegar sementes em um jardim vizinho e plantá-las no local onde morava a florzinha) ao conhecimento de mundo da criança (flores nascem a partir de sementes que são plantadas, e que juntas formam um jardim).

Quanto à quinta pergunta ("O que fez as sementes crescerem tão rápido?"), a resposta correta requeria integrar o fato de ter chovido à noite, após as sementes terem sido plantadas, com o conhecimento de mundo de que é necessário água para que as sementes brotem, cresçam e se transformem em flores.

Na sexta pergunta ("Quem eram as amigas da florzinha no final da história?"), a resposta apropriada requeria inferir que as amigas seriam as flores que haviam crescido a partir das sementes plantadas pelo passarinho.

\subsubsection{O texto argumentativo}

No texto argumentativo, as perguntas inferenciais de estado incidiam sobre os personagens e suas opiniões, isto é, sobre os pontos de vista diferentes acerca do tema tratado no texto; enquanto as perguntas causais se referiam às justificativas que sustentavam os pontos de vista divergentes dos personagens.

Quadro 2 - Perguntas inferenciais relativas ao texto argumentativo

\begin{tabular}{|l|l|}
\hline \multicolumn{2}{|c|}{ Texto argumentativo } \\
\hline \multicolumn{1}{|c|}{ Pergunta } & Tipo \\
\hline $\begin{array}{l}\text { 1. Por que os animais grandes acham que } \\
\text { é mais seguro ser grande na floresta? }\end{array}$ & Causal \\
\hline $\begin{array}{l}\text { 2. Por que os animais pequenos acham que } \\
\text { é mais seguro ser pequeno na floresta? }\end{array}$ & Causal \\
\hline $\begin{array}{l}\text { 3. Como os animais pequenos conse- } \\
\text { guem fugir do perigo? }\end{array}$ & Estado \\
\hline $\begin{array}{l}\text { 4. Como os animais grandes conseguem } \\
\text { fugir do perigo? }\end{array}$ & Estado \\
\hline $\begin{array}{l}\text { 5. Onde vivem estes animais: na terra ou } \\
\text { na água? }\end{array}$ & Estado \\
\hline $\begin{array}{l}\text { 6. Por que os animais não iam conseguir } \\
\text { aproveitar tudo que a floresta tem se } \\
\text { fossem todos do mesmo tamanho? }\end{array}$ & Causal \\
\hline
\end{tabular}

Fonte: As autoras.

Para responder a primeira pergunta ("Por que os animais grandes acham que é mais seguro ser grande na floresta?") de forma apropriada, seria necessário identificar as características dos animais grandes que permitiriam sobreviver na floresta, como a capacidade de andar no rio sem se afogar e ter uma boa visão do alto para identificar possiveis inimigos.

Na segunda pergunta ("Por que os animais pequenos acham que é mais seguro ser pequeno na floresta?"), a resposta apropriada, semelhante ao que ocorre na primeira pergunta, seria ser capaz de identificar as caracteristicas dos animais pequenos que permitiriam sobreviver na floresta, como serem rápidos e de pequeno porte.

Responder corretamente a terceira pergunta ("Como os animais pequenos conseguem fugir do perigo?") requeria associar as caracteristicas desses animais às ações que podem realizar quando se sentem em perigo, como por exemplo, correr rapidamente e se esconderem com facilidade.

De forma análoga, para responder a quarta pergunta ("Como os animais grandes conseguem fugir do perigo?") seria necessário associar as ca- 
racteristicas desses animais às ações que podem realizar para fugirem do perigo, como fugir pelo rio e enxergar as coisas de longe.

A resposta apropriada a quinta pergunta ("Onde vivem estes animais: na terra ou na água?") requeria pensar no cenário em que vivem os animais mencionados no texto, no caso a floresta, e no conhecimento de mundo sobre florestas, que se localizam em terra firme.

Para responder a sexta pergunta ("Por que os animais não iam conseguir aproveitar tudo que a floresta tem se fossem todos do mesmo tamanho?") seria necessário compreender que o tamanho dos animais determina o modo como podem se divertir na floresta. Se fossem todos pequenos nunca iriam andar nos rios, ou pegar frutos nos lugares mais altos, e se fossem todos grandes não iriam ganhar quando brincassem de correr e nem se esconderem em lugares apertados.

\subsubsection{O texto expositivo}

No texto expositivo, as perguntas inferenciais de estado versavam sobre as características dos animais e do seu habitat. As perguntas inferenciais causais se referiam às relações estabelecidas entre passagens do texto.

Quadro 3 - Perguntas inferenciais relativas ao texto expositivo

\begin{tabular}{|c|c|}
\hline \multicolumn{2}{|l|}{ Texto expositivo } \\
\hline Pergunta & Tipo \\
\hline $\begin{array}{l}\text { 1. Qual é o animal mais pesado: a girafa ou } \\
\text { o leão? }\end{array}$ & Estado \\
\hline 2. Por que as girafas não são todas iguais? & Causal \\
\hline $\begin{array}{l}\text { 3. Por que elas não comem folhas que } \\
\text { estão caídas no chão? }\end{array}$ & Causal \\
\hline $\begin{array}{l}\text { 4. Qual a vantagem que a girafa tem em } \\
\text { ser alta? }\end{array}$ & Estado \\
\hline $\begin{array}{l}\text { 5. Quando é que a girafa fica mais despro- } \\
\text { tegida? }\end{array}$ & Estado \\
\hline $\begin{array}{l}\text { 6. Porque quando está erguida, a girafa } \\
\text { percebe o inimigo, mesmo quando ele } \\
\text { está longe? }\end{array}$ & Causal \\
\hline
\end{tabular}

Fonte: As autoras.
Para responder, de forma apropriada, a primeira pergunta ("Qual é o animal mais pesado: a girafa ou o leão?") seria necessário considerar a passagem que menciona que a girafa "[...], perdendo apenas para o elefante e o rinoceronte em peso." Isso quer dizer que apenas esses animais são mais pesados que a girafa, logo, infere-se que o leão é menos pesado que ela.

Na segunda pergunta ("Por que as girafas não são todas iguais?"), seria necessário inferir que as manchas do corpo das girafas é que fazem com que cada uma seja diferente da outra.

Para responder a terceira pergunta ("Por que elas não comem folhas que estão caidas no chão?") seria preciso considerar que ao baixar a cabeça para comer as folhas do chão a girafa não consegue ver o inimigo se aproximando. Aqui seria necessário fazer uma analogia com o que ocorre em relação ao ato de beber água mencionado no texto.

A resposta apropriada para a quarta pergunta ("Qual a vantagem que a girafa tem em ser alta?") seria que, por ser alta, a girafa pode ver o inimigo de longe e se proteger dele.

Para responder a quinta pergunta ("Quando é que a girafa fica mais desprotegida?") seria necessário compreender que isso ocorre quando ela baixa a cabeça para beber água, pois ao fazer isso, não consegue ver o leão se aproximando, ficando desprotegida.

A resposta apropriada à sexta pergunta ("Porque quando está erguida, a girafa percebe o inimigo, mesmo quando ele está longe?") estaria associada ao fato de que, devido à sua altura, a girafa consegue ter uma ampla visão da floresta, inclusive ver o que está longe dela.

\section{Resultados}

Os dados foram analisados em função do número de acertos em cada pergunta. Exemplos das respostas dadas pelas crianças são apresentados no Quadro 4, onde se pode observar tanto respostas corretas como incorretas ${ }^{8}$. 
Quadro 4 - Exemplos de respostas corretas e incorretas em cada tipo de texto

\begin{tabular}{|c|c|c|c|}
\hline Tipo de texto & Pergunta Inferencial & $\begin{array}{l}\text { Resposta } \\
\text { Incorreta }\end{array}$ & Resposta Correta \\
\hline \multirow{2}{*}{ Narrativo } & $\begin{array}{l}\text { Por que as árvores grandes } \\
\text { não gostavam da flor? (Causal) }\end{array}$ & $\begin{array}{l}\text { Porque árvore não } \\
\text { fala. }\end{array}$ & $\begin{array}{l}\text { Porque a flor era mais bonita do } \\
\text { que elas, porque ela chamava } \\
\text { mais atenção. }\end{array}$ \\
\hline & $\begin{array}{l}\text { O que foi que o passarinho fez } \\
\text { para ajudar a flor? (Estado) }\end{array}$ & Parar de ficar triste. & $\begin{array}{l}\text { Plantou sementes e nasceu flores } \\
\text { para ser as amigas delas. }\end{array}$ \\
\hline \multirow[t]{2}{*}{ Argumentativo } & $\begin{array}{l}\text { Por que os animais grandes } \\
\text { acham que é mais seguro ser } \\
\text { grande na floresta? (Causal) }\end{array}$ & $\begin{array}{l}\text { Porque são mais } \\
\text { fortes. }\end{array}$ & $\begin{array}{l}\text { Por causa que eles consegue ver } \\
\text { mais coisas do alto, pegar frutos de } \\
\text { arvore bem grande, também não } \\
\text { se afogar em mares muito fundos. }\end{array}$ \\
\hline & $\begin{array}{l}\text { Como os animais pequenos } \\
\text { conseguem fugir do perigo? } \\
\text { (Estado) }\end{array}$ & $\begin{array}{l}\text { Porque são mais } \\
\text { menores e os outros } \\
\text { são mais grandes. }\end{array}$ & Pode se esconder ou correr. \\
\hline \multirow[t]{2}{*}{ Expositivo } & $\begin{array}{l}\text { Porque quando está erguida a } \\
\text { girafa percebe o inimigo, mes- } \\
\text { mo quando ele está longe? } \\
\text { (Causal) }\end{array}$ & $\begin{array}{l}\text { Porque tem um dia } \\
\text { que ele vai atacar e } \\
\text { tem dia que não. }\end{array}$ & $\begin{array}{l}\text { Porque ela tem um pescoço mui- } \\
\text { to longo dá pra ver as coisas. Ela } \\
\text { pode fazer assim: ela tá aqui, ai o } \\
\text { leão tá do outro, ela pode mexer } \\
\text { a cabeça um pouquinho e ver, ai } \\
\text { ela sai correndo. }\end{array}$ \\
\hline & $\begin{array}{l}\text { Quando é que a girafa fica } \\
\text { mais desprotegida? (Estado) }\end{array}$ & Quando tocam nela. & $\begin{array}{l}\text { Quando ela tá bebendo água, } \\
\text { por que ela abre as pernas e } \\
\text { abaixa o pescoço. }\end{array}$ \\
\hline
\end{tabular}

Fonte: As autoras.

Comparações quanto ao desempenho foram feitas por meio do teste de Wilcoxon que revelou haver diferenças significativas apenas entre o texto narrativo e argumentativo $(Z=-3,263 ; p=$ .001) e ente o narrativo e o expositivo $(Z=-3,614$; $\mathrm{p}=.000$ ). Isso ocorreu porque o percentual de acertos no texto narrativo (78,3\%) foi significativamente maior do que no texto argumentativo $(57,8 \%)$ e no expositivo (51,1\%). Não foram identificadas diferenças entre o texto expositivo e argumentativo $(Z=-1,760 ; p=.078)$. De acordo com esses resultados, as crianças tinham mais facilidade em compreender o texto narrativo que os demais textos, apresentando o mesmo nivel de dificuldade no texto expositivo e argumentativo.

Com o objetivo de examinar a influência do tipo de pergunta (causal e estado) sobre o desempenho em cada texto, foi elaborada a Tabela 1.
TABELA 1 - Número e percentual (entre parênteses) de respostas corretas em cada tipo de pergunta e em cada tipo de texto (máximo: 90)

\begin{tabular}{|l|l|l|l|}
\hline Perguntas & Narrativo & Argumentativo & Expositivo \\
\hline Causal & $71(78,9)$ & $54(60)$ & $31(34,4)$ \\
\hline Estado & $70(77,8)$ & $50(55,6)$ & $61(67,8)$ \\
\hline
\end{tabular}

Fonte: As autoras.

Inicialmente foram realizadas comparações entre os tipos de perguntas em cada texto. Como pode ser visto, a natureza da inferência envolvida nas perguntas não teve um impacto no desempenho observado no texto narrativo e nem tampouco no texto argumentativo, sendo isso confirmado pelo Wilcoxon que não identificou diferenças significativas na frequência de acertos entre perguntas causais e de estado no texto narrativo $(Z=-0,258 ; p=$ 
796) e no argumentativo ( $Z=-0,683 ; p=.495)$. Como mostra a Tabela 1, no texto narrativo as crianças tiveram o mesmo bom desempenho nos dois tipos de perguntas (causal: 78,9\%; estado: $77,8 \%$ ), enquanto no texto argumentativo o mesmo desempenho limitado foi observado nas duas perguntas (causal: 60\%; estado: 55,6\%). Contudo, diferenças significativas foram encontradas entre os tipos de perguntas no texto expositivo ( $Z=-3.581 ; p=.000$ ), uma vez que o desempenho foi melhor nas perguntas de estado $(67,8 \%)$ do que nas causais (34,4\%).

Por meio do Wilcoxon, foram realizadas comparações entre os textos em cada tipo de pergunta, sendo os valores de significância obtidos apresentados na Tabela 2.

TABELA 2 - Valores de significância obtidos no teste de Wilcoxon na comparação entre os tipos de textos em cada tipo de pergunta

\begin{tabular}{|l|l|l|}
\hline \multicolumn{1}{|c|}{$\begin{array}{c}\text { Comparações } \\
\text { entre textos }\end{array}$} & $\begin{array}{c}\text { Perguntas } \\
\text { causais }\end{array}$ & $\begin{array}{c}\text { Perguntas } \\
\text { de estado }\end{array}$ \\
\hline $\begin{array}{l}\text { Narrativo vs. } \\
\text { Argumentativo }\end{array}$ & $\mathrm{Z}=-2,528^{\mathrm{a}}$ & $\mathrm{Z}=-2,708^{\mathrm{a}}$ \\
$\mathrm{p}=.011^{*}$ & $\mathrm{p}=.007^{*}$ \\
\hline Narrativo vs. & $\mathrm{Z}=-4,271^{\mathrm{a}}$ & $\mathrm{Z}=-1,237^{\mathrm{a}}$ \\
Expositivo & $\mathrm{p}=.000^{* *}$ & $\mathrm{p}=.216$ \\
\hline Argumentativo vs. & $\mathrm{Z}=-3,011^{\mathrm{a}}$ & $\mathrm{Z}=-1,947^{\mathrm{a}}$ \\
Expositivo & $\mathrm{p}=.003^{* *}$ & $\mathrm{p}=.052$ \\
\hline
\end{tabular}

Fonte: As autoras.

Notas: $1{ }^{*} p<.052,{ }^{* *} p<.01$

O desempenho nas perguntas causais foi melhor no texto narrativo do que nos demais textos. Nas perguntas de estado a única diferença significativa foi entre o texto narrativo e argumentativo, uma vez que o percentual de acertos foi maior no texto narrativo que no argumentativo.

Tomados de forma conjunta, os resultados mostram que as perguntas de causalidade são particularmente difíceis para as crianças no texto expositivo e as perguntas de estado tendem a ser mais dificeis no texto argumentativo. As possiveis razões para essas dificuldades, particulares a cada tipo de texto, são discutidas adiante.

\section{Conclusões e discussão}

Duas conclusões surgem como importantes a partir dos dados obtidos nesta pesquisa. A primeira delas se refere ao objetivo principal que era avaliar se o nivel de compreensão variaria em função do tipo de texto apresentado à criança. Para isso, a compreensão dos participantes foi comparada em textos narrativo, expositivo e argumentativo. Os resultados mostraram que o nivel de compreensão variava em função dos textos, visto que as crianças apresentaram um bom nivel de compreensão no texto narrativo; contudo, apresentaram um desempenho igualmente limitado em relação aos textos expositivo e argumentativo. Uma possivel explicação para isso é a pouca familiaridade que as crianças da Educação Infantil têm com esses textos, tanto no ambiente escolar, como no ambiente familiar, em oposição à história que é, sem dúvida, o texto que circula frequentemente e desde muito cedo em casa e na escola, cumprindo funções lúdicas e didáticas.

Importante ressaltar que o bom desempenho na compreensão de histórias em comparação a outros textos não se limita a crianças da Educação Infantil. Como mencionado anteriormente, mesmo crianças maiores de 9 anos demonstram mais facilidade em compreender textos narrativos que expositivos (BASTUG, 2014; ÇAKIR, 2008; MCNAMARA; OZURU; FLOYD, 2011). Parece que o conhecimento sobre o esquema narrativo, ainda que adquirido de maneira informal e inicial, favorece a compreensão de histórias. Por outro lado, tanto o texto argumentativo como o expositivo não possuem uma estrutura prototípica tão definida quanto a história, e isso talvez explique a dificuldade observada em relação a esses textos, mesmo em idades e anos escolares mais adiantados. Além disso, textos expositivos se propõem a apresentar informações novas sobre algo; de maneira que o conhecimento das crianças sobre o conteúdo veiculado no texto era limitado. Em relação ao texto argumentativo, as limitações na compreensão podem decorrer também da dificuldade em associar um ponto de vista a um dado personagem ou à justificativa que o sustenta. Isso parece ocorrer mesmo entre crianças mais velhas, como documentado por Almeida, Spinillo e Lima (2019)

A segunda conclusão versa sobre o objetivo especíico de identificar a natureza das dificulda- 
des. Para isso, a compreensão dos textos envolveu a análise do desempenho em relação a dois tipos de inferências que foram examinadas por meio de perguntas que versavam sobre relações de causalidade e acerca de informações sobre locais, eventos, sentimentos, opiniões, motivação e características dos personagens tratados nos textos. No texto narrativo, observou-se o mesmo bom nivel de compreensão nos dois tipos de perguntas e no texto argumentativo observou-se uma compreensão limitada nos dois tipos de perguntas. Na realidade, a natureza da inferência só teve impacto na compreensão do texto expositivo, já que as perguntas de estado foram mais fáceis de serem respondidas que aquelas que versavam sobre a causalidade. A conclusão foi que a principal dificuldade das crianças dessa faixa etária e segmento escolar reside na compreensão da causalidade no texto expositivo. Todavia, as crianças demonstraram dificuldades tanto nas perguntas de estado como de causalidade em relação ao texto argumentativo. Tomados de forma conjunta, conclui-se que a natureza da dificuldade não se aplica a todos os tipos de textos e que a compreensão das relações de causalidade é um desafio para as crianças desse segmento escolar e faixa etária. Essa dificuldade, entretanto, não é identificada em relação a textos que lhes são familiares, como a história.

Esse resultado tem implicações educacionais relevantes, pois conhecendo as dificuldades com as quais as crianças se deparam ao tentar compreender textos pouco familiares, torna-se necessário pensar sobre formas de superá-las. Nesse sentido, sabendo do importante papel que a compreensão oral de textos possui na compreensão leitora posterior, como mencionado no início deste artigo, torna-se necessário pensar em formas de promover intervenções precoces para desenvolver a compreensão oral de textos antes mesmo de a criança estar alfabetizada. Tal possibilidade credita à Educação Infantil um papel ainda mais relevante no desenvolvimento de habilidades linguísticas que vão além do conhecimento do vocabulário e da capacidade de decodificação, aspectos esses que já são considerados no último ano desse segmento escolar. Essas habilidades linguísticas que precisam ser desenvolvidas envolvem conhecimentos sobre as relações estabelecidas entre as proposições do texto.

Broek et al. (2011) discutem potenciais aplicações de intervenções precoces em crianças ainda não alfabetizadas e em processo de alfabetização. A ênfase das discussões, conduzidas a partir de resultados documentados na literatura na área e a partir de dois estudos realizados pelos autores com crianças não leitoras e leitoras iniciantes, recaia sobre intervenções que envolviam a técnica de questionamento sobre relações causais. De acordo com os autores, fazer perguntas sobre o texto é uma maneira eficiente de ajudar a criança a construir uma representação mental coerente do texto, uma vez que direcionam a atenção para o estabelecimento de conexões entre informações nele veiculadas (implicitas ou explícitas), em especial as relações de causalidade. Além da natureza da pergunta, foi enfatizada a importância do momento em que a pergunta é feita, visto que o avanço na compreensão foi mais expressivo quando as perguntas eram feitas durante a apresentação do texto mais do que quando feitas após a apresentação. Vale a pena comentar que resultado semelhante foi encontrado por Spinillo e Hodges (2013) ao comparar diferentes situações de leitura, verificando que a situação mais proveitosa era a leitura interrompida (metodologia on-line) em que perguntas eram feitas na medida em que partes do texto eram apresentadas.

O estudo conduzido por Broek et al. (2011) foi realizado com textos narrativos, mas é possivel supor que uma intervenção baseada em perguntas de causalidade possa também promover a compreensão de outros tipos de textos, como argumentativo e expositivo. Uma intervenção precoce, ainda durante os anos finais da Educação Infantil, poderia contribuir para superar, inclusive, as dificuldades que as crianças apresentam com as inferências acerca de relações de causalidade, como identificado na presente investigação. É possivel supor, ainda, que não apenas perguntas de causalidade sejam capazes de promover a compreensão, mas também perguntas de estado. 
Estudos de intervenção com essa população baseados na técnica de questionamento com vistas a desenvolver a compreensão oral de textos seriam relevantes tanto do ponto de vista cognitivo como educacional.

A compreensão oral de textos desempenha papel importante na compreensão leitora posterior. como pressupõe o modelo simples de leitura de Hoover e Gough (1990). Tal afirmação é corroborada por evidências empíricas, como reiterado por Kim (2016) e Tompkins, Guo e Justice (2013) ao comentarem que a compreensão oral de textos é uma habilidade complexa que demanda mais do que o domínio do vocabulário; e que, assim como a compreensão leitora, envolve habilidades cognitivas de alta ordem como estabelecimento de inferências. Na presente pesquisa, as inferências de causalidade foram um desafio para as crianças investigadas em relação ao texto argumentativo e, em especial, ao texto expositivo. Assim, é necessário auxiliar as crianças a, desde cedo, superarem a dificuldade em estabelecer esse tipo de inferência, de modo a tornarem-se, futuramente, leitoras competentes não apenas de textos narrativos, mas de textos outros que são fundamentais para seu sucesso acadêmico e social. Isso é de particular importância em relação a textos expositivos, visto que por meio deles são apresentados muitos dos conteúdos escolares.

Para finalizar, o presente estudo procurou contribuir com informações acerca das relações entre compreensão de textos e tipos de textos; mas, sobretudo, com informações acerca dos limites e possibilidades que crianças que ainda não leem apresentam diante do desafio de compreender textos. Como implicação educacional, a contribuição é no sentido de se pensar em intervenções precoces que levem as crianças da Educação Infantil a desenvolverem a compreensão oral de textos.

\section{Agradecimentos}

As autoras agradecem o auxílio concedido pelo Conselho Nacional de Desenvolvimento Científico e Tecnológico (CNPq) sob forma de bolsa de estudos conferida à primeira autora para realização de doutorado, sob a orientação da segunda autora, no Programa de Pós-Graduação em Psicologia Cognitiva da UFPE. Agradecimentos são também endereçados às escolas que colaboraram com a coleta de dados e às crianças que participaram desse estudo.

\section{Referências}

ALMEIDA, Denise Dias; SPINILLO, Alina Galvão; LIMA, Ilka Dayanne Medrado. Compreensão de texto argumentativo em crianças. Letras de Hoje, Porto Alegre, v. 54, n. 2, p. 202-210, abr./jun. 2019

BARETTA, Luciane; TOMITCH, Lêda Maria Braga; MCNAIR, Nicolas; LIM, Vanessa Kwan; WALDIE, Karen Elisabeth. Inference making while reading narrative and expository texts: An ERP study. Psychology \& Neuroscience, [S. I.], v. 2, n. 2, p. 137-145, 2009.

BAŞTUĞ, Muhammet. Comparison of reading comprehension with respect to text type, grade level and test type. International Online Journal of Educational Sciences, [S. I.], v. 6. n. 2, p. 281-291, 2014.

BERNINGER, Virginia Wise; ABBOTT, Robert D. Listening comprehension, oral expression, reading comprehension and written expression: Related yet unique language systems in grades $1,3,5$, and 7 . Journal of Educational Psychology, [S. I.], v. 102, n. 3, p. 635-651, 2010.

BRANDÃO, Ana Carolina Perrusi; SPINILLO, Alina Galvão. Aspectos gerais e especíicos na compreensão de textos. Psicologia Reflexão e Crítica, [S. I.], v. 11, n. 2, p. 253-272, 1998.

BRANDÃO Ana Carolina Perrusi; OAKHILL, Jane. "How do you know this answer?" - Children's use of text data and general knowledge in story comprehension. Reading and Writing, [S. I.], v. 18, p. 687-713, 2005.

CAIN, Kate; OAKHILL, Jane. Reading comprehension difficulties: Correlates, causes, and consequences. In: CAIN, Kate; OAKHILL, Jane. (ed.), Children's comprehension problems in oral and written language: A cognitive perspective. New York: Guilford Press, 2007. p. 41-75.

COSCARELLI, Carla Viana. Reflexões sobre as inferências. In: CONGRESSO BRASILEIRO DE LINGUISTICA APLICADA, 6., 2002, Belo Horizonte. Anais [...]. Belo Horizonte: Faculdade de Letras, 2002. CD-ROM.

ÇAKIR, Ozler. The effect of textual differences on children's processing strategies. Reading Improvement. ProQuest Educational Journals, [S. I.], v. 45, n. 2, p. 69-83, 2008.

DIAKIDOY, Irene-Anna N.; CHRISTODOULOU, Stelios A. FLOROS, Georgios; IORDANOU Kalypso; KARGOPOULOS, Philip V. Forming a belief: The contribution of comprehension to the evaluation and persuasive impact of argumentative text. British Journal of Educational Psychology, [S. I.], v. 85, n. 3, p. 300-315, 2015.

DIAKIDOY, Irene-Anna N.; IOANNOU, Melina C.; CHRISTODOULOU, Stelios A. Reading argumentative texts: comprehension and evaluation goals and outcomes. Reading and Writing, [S. I.], n. 30, v. 9. p. 1869-1890, 2017. 
DIAKIDOY, Irene-Anna NL. et al.. The relationship between listening and reading comprehension of different types of text at increasing grade levels. Reading Psychology, [S. I.], v. 26, n. 1, p. 55-80, 2005. DOI: 10.1080/02702710590910584.

GRAESSER, Arthur C.; SINGER, Murray; TRABASSO, Tom. Constructing inferences during narrative text comprehension. Psychological Review, [S. I.], v. 101, n. 3. p. 371-395, 1994.

HOOVER, Wesley A.; GOUGH, Philip B. The simple view of reading. Reading and Writing, IS. I.], v. 2, p. 127-60, 1990.

KENDEOU, Panayiora; BROEK, Paul van den. The effects of prior knowledge and text structure on comprehension processes during reading of scientific texts. Memory and Cognition, [S. I.], v. 35, n. 7. p. 1567-1577, 2007.

KENDEOU, Panayiora et al.. Predicting reading comprehension in early elementary school: The independent contributions of oral language and decoding skills. Journal of Educational Psychology, [S. I.], v. 101, n. 4, p. 765-778, 2009

KIM, Young-Suk Grace. Directed and mediated effects of language and cognitive skills on comprehension of oral narrative texts (listening comprehension) for children. Journal of Experimental Child Psychology, IS. l.], v. 141, p. 101-120, 2016.

KING, Alison. Beyond Literal Comprehension: A strategy to promote deep understanding of text. In: McNAMARA, Danielle S. Reading Comprehension Strategies: theories, interventions and technologies. New York: Taylor \& Francis Group, 2007. p. 267-290.

KINTSCH, Walter. Comprehension: a paradigm for cognition. Cambridge, MA: Cambridge University Press, 1998.

LEPOLA, Janne; LYNCH, Julie; LAAKKONEN, Eero; SILVÉN, Maarit; NIEMI, Pekka. The role of inference making and other language skills in the development of narrative listening comprehension in 4-6-year- old children. Reading Research Quarterly, [S. I.], v. 47, n. 3, p. 259-282, 2012.

MARCUSCHI, Luiz Antônio. Produção textual, análise de gêneros e compreensão. São Paulo: Parábola Editorial, 2008.

MCNAMARA, Danielle S; OZURU, Yasuhiro; FLOYD, Randy G. Comprehension challenges in the fourth grade: the roles of text cohesion, text genre, and readers' prior knowledge. International Electronic Journal of Elementary Education, [S. I.], v. 4, n. 1, p. 229-257, 2011.

MCNAMARA, Danielle S. Reading Comprehension Strategies: theories, interventions and technologies. New York: Taylor \& Francis Group, 2007.

MELO, Lianny Milenna de Sá. Compreensão de textos em crianças: uma análise das relações entre tipos de textos e inferências. 2017. 149 f. Tese (Doutorado em Psicologia Cognitiva) - Universidade Federal de Pernambuco, Recife, 2017.

OZURU, Yasuhiro; BEST, Rachel; BELL, Courtney; WITHERSPOON, Amy; McNAMARA, Danielle S. Influence of question format and text availability on the assessment of expository text comprehension. Cognition and Instruction, [S. I.], v. 25, n. 4, p. 399-438, 2007.
SARAIVA, Rosália Alvim; MOOJEN, Sônia Maria Pallaoro; MUNARSKI, Roberta. Avaliação da compreensão leitora de textos expositivos: para fonoaudiólogos e psicopedagogos. 2. ed. São Paulo: Casa do Psicólogo, 2009.

SPINILLO, Alina. Galvão. A dimensão social, linguística e cognitiva da compreensão de textos: considerações teóricas e aplicadas. In: MOTA, Marcia Peruzzi E.; SPINILLO, Alina Galvão. Compreensão de textos: processos e modelos. São Paulo: Casa do Psicólogo, 2013. p. 171-198.

SPINILLO, Alina Galvão; ALMEIDA, Denise Dias. Compreendendo textos narrativo e argumentativo: há diferenças? Arquivos Brasileiros de Psicologia, Rio de Janeiro, v. 66, n. 3, p. 115-132, 2014.

SPINILLO, Alina Galvão; HODGES, Luciana Vasconcelos dos Santos Dantas. Situações de leitura e o estabelecimento de inferências por crianças com dificuldades de compreensão de textos. In: ROAZZI, Antonio.; JUSTI, Francis Ricardo dos Reis; SALLES, Jerusa Fumagalli de (org.). A aprendizagem da leitura e da escrita: contribuições de pesquisas. São Paulo: Vetor, 2013. p. 131-164.

SPINILLO, Alina Galvão; MAHON, Érika da Rocha. "O que você acha que vai acontecer agora?" Um estudo sobre as inferências de previsão na compreensão de textos. In: NASCHOLD, Angela Chuvas et al.(org.). Aprendizado da leitura e da escrita: a ciência em interface. Natal: Ed. da Universidade Federal do Rio Grande do Norte, 2015. p. 163-192.

TENGBERG, Michael; OLIN-SCHELLER, Christina. Developing critical reading of argumentative text: Effects of a comprehension strategy intervention. Journal of Language Teaching and Research, [S. I.], v. 7, n. 4, p. 635-645, 2016.

TOBIA, Valentina; BONIFACCI, Paola. The simple view of reading in a transparent orthography: The stronger role of oral comprehension. Reading and Writing, [S. I.], v. 28, n. 7, p. 939-957, 2015

TOMPKINS, Virgina; GUO, Ying; JUSTICE, Laura M. Inference generation, story comprehension, and language in the preschool years. Reading and Writing, [S. I.], v. 26, p. 403-429, 2013.

van den BROEK, Paul; KENDEOU, Panayiora; LOUSBERG, Sandra; VISSER, Gootje. Preparing for reading comprehension: Fostering text comprehension skills in preschool and early elementary school children. International Electronic Journal of Elementary Education, [S. I.], v. 4, n. 1, p. 259-268, 2011.

WOLFE, Michael B. W. Narrative and expository text: independent influences of semantic associations and text organization. Journal of Experimental Psychology: Learning, Memory, and Cognition, [S. I.], v. 31, n. 2, p. 359-364, 2005. 


\section{Apêndice A - Texto argumentativo}

Os animais e a floresta

A floresta é um lugar muito legal. Lá moram animais de todo tipo: grandes e pequenos, que rastejam, que nadam, que voam; bravos e mansos.

Os animais grandes, como o elefante, o rinoceronte e a girafa, dizem que com seus tamanhos é muito mais fácil viver na floresta. Eles conseguem andar por dentro dos rios sem se afogar, pegar os frutos nos lugares mais altos e ter uma boa visão de tudo que acontece na floresta.

Já os animais pequenos, como o macaco, o lobo e o coelho, acham que é muito mais legal ser pequeno. Eles conseguem se esconder mais facilmente na floresta, ganham todas as brincadeiras de correr porque são mais velozes e passam por todos os lugares, mesmo os mais apertados.

Ao pensarmos sobre as diversas características dos animais, podemos entender que o tamanho muda o jeito de cada animal viver e se divertir na floresta. Mas essas diferenças não podem ser vistas como um problema. Será que os animais iam conseguir aproveitar tudo da floresta se todos eles fossem iguais?

Fonte: As autoras.

\section{Anexo A - Texto narrativo}

Florzinha

Era uma vez uma flor que morava em um quintal cheio de árvores grandes e feias. A flor era muito bonita e delicada e chamava a atenção de todos que por lá passavam. Mas a flor vivia muito triste, pois não havia ninguém com quem pudesse conversar. As árvores grandes não gostavam dela e nunca a convidavam para brincar. Um dia, a flor viu um passarinho e resolveu conversar com ele. Ela foi logo dizendo que estava muito triste.

- Por que você está tão triste? perguntou o passarinho.

- Aqui fico muito sozinha, disse a flor. Não tenho amigos. Você poderia ajudar?

- Não se preocupe, respondeu o passarinho, tenho uma ideia para acabar com sua tristeza. E lá foi ele voando rápido para um jardim vizinho.

Nesse jardim o passarinho apanhou com o bico várias sementes de flores. À noite, voltou para o quintal onde a florzinha morava e enquanto ela dormia, plantou as sementes na terra. Naquela noite, choveu muito. Ao amanhecer, a flor teve uma grande surpresa. O quintal parecia um lindo jardim! Desde então, a flor viveu muito feliz, pois agora tinha muitas amigas para conversar.

Fonte: Adaptado de BRANDÃO, Ana Carolina Perrusi; SPINILLO, Alina Galvão. Aspectos gerais e específicos na compreensão de textos. Psicologia: Reflexão e Critica, [S. /], v. 11, n. 2, p. 253-272, 1998.

\section{Anexo B - Texto expositivo}

\section{A Girafa}

A girafa vive na África. Seu nome, em árabe 'zarafa', quer dizer 'aquele que anda rapidamente'.

É o animal mais alto da Terra e também um dos mais pesados, perdendo apenas para o elefante e o rinoceronte em peso. Seu corpo é coberto por um pelo amarelado cheio de manchas que são diferentes de um animal para o outro. A girafa raramente emite sons.

Ela vive em bandos de 12 a 15 animais, formados por um macho, suas fêmeas e filhotes.

Por causa da sua altura, ela se alimenta das folhas novas que ficam na parte superior das árvores altas.

O inimigo natural das girafas é o leão, que procura atacá-la quando ela está bebendo água. Esse é o melhor momento, porque ela tem que abrir suas longas pernas dianteiras e abaixar seu pescoço comprido para alcançar a água, ficando assim, desprotegida.

Quando está erguida, a girafa percebe o inimigo de longe e se defende com patadas violentas. Por isso, como forma de proteção, a girafa geralmente dorme em pé.

Fonte: Adaptado de SARAIVA, Rosália Alvim; MOOJEN, Sônia Maria Pallaoro; MUNARSKI, Roberta. Avaliação da compreensão leitora de textos expositivos: para fonoaudiólogos e psicopedagogos. 2. ed. São Paulo: Casa do Psicólogo, 2009. 


\section{Jacqueline Travassos de Queiroz}

Doutora em Psicologia Cognitiva pela Universidade Federal de Pernambuco (UFPE), em Recife, PE, Brasil. Membro Núcleo de Estudos em Educação Cognitiva (do NUEEC), da Universidade de Pernambuco (UPE), em Recife, PE, Brasil; professora adjunta da UPE, em Garanhuns, PE, Brasil, no Departamento de Psicologia. Psicóloga Escolar e Educacional.

\section{Alina Galvão Spinillo \\ Professora Titular da Pós-Graduação em Psicologia Cognitiva da Universidade Federal de Pernambuco (UFPE), em Recife, PE, Brasil; atua como docente e orientadora de alunos de Graduação, de mestrado e de doutorado. Líder no Núcleo de Pesquisa em Psicologia da Educação Matemática (NUPPEM); pesquisadora Nivel 1 do CNPq}

\section{Lianny Milenna de Sá Melo}

Doutora em Psicologia Cognitiva pela Universidade Federal de Pernambuco (UFPE), em Recife, PE, Brasil; professora do Centro Universitário Brasileiro (UNIBRA), em Recife, PE, Brasil.

\section{Endereço para correspondência}

Jacqueline Travassos De Queiroz

Universidade de Pernambuco

Rua Capitão Pedro Rodrigues, s/n

São José, 55294902

Garanhuns, PE, Brasil 